\title{
A Case Study of Pharmacovigilance in Nigeria: Challenges and Solutions
}

\author{
Kingsley Akarowhe* \\ Department of Educational Foundations, Guidance and Counselling, University of Uyo, Nigeria
}

*Corresponding author: Kingsley Akarowhe, Department of Educational Foundations, Guidance and Counselling, Faculty of Education, University of Uyo, Nigeria.

To Cite This Article: Kingsley Akarowhe, A Case Study of Pharmacovigilance in Nigeria: Challenges and Solutions. 2020 - 10(1). AJBSR.MS.ID.001470. DOI: $10.34297 /$ AJBSR.2020.10.001470.

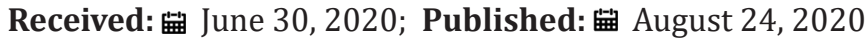

\begin{abstract}
Pharmacovigilance is concern with the monitoring and examining of drugs to prevent its adverse effect on patients in a given nation. In spite, of the intensive efforts made by the Nigeria government to improve pharmacovigilance little seems to be achieved. This may be due to the challenges faced by the national pharmacovigilance centre (NPC) which range from lack of skilled manpower, lack of sufficient funding among others. Due to these underlining facts, Nigeria government, citizens and health stakeholders often map-out modalities for ensuring effective and efficient pharmacovigilance, but much result have not been achieved as anticipated. It is a consonance with the forgoing that the researcher carried out an investigative approach into the challenges facing pharmacovigilance in Nigeria with solution insight for the challenges. It was recommended among others that, the Nigeria Government should ensure that only qualified persons especially pharmacologist are employed in National Pharmacovigilance Centre (NPC).
\end{abstract}

Keywords: Pharmacovigilance; Challenges; Solutions; Component; Nigeria

Abbreviations: NPC: National Pharmacovigilance Centre; Phv: Pharmacovigilance; ADRs: Adverse Drug Reactions; NAFDAC: Food and Drug Administration and Control; NPC: National Pharmacovigilance Centre; QPPV: Qualified Person for Pharmacovigilance; SOPs: Standard Operation Procedure

\section{Overview of Pharmacovigilance}

The term pharmacovigilance connotes varied meaning to different health stakeholders in the field of science. Notwithstanding, it must revolves round adverse effect of drugs. In line with this, pharmacovigilance is a process that encompasses all the activities involves in the monitory, testing, surveying drugs to prevent it's negative effect on patients. In same similitude [1] contended that pharmacovigilance (PV or Phv) is also called drug safety, is the pharmacological science relating to the collection, detection, assessment, monitoring, and preventing of adverse effects with pharmaceutical products. Pharmacovigilance is a special branch of science that is concern with drug safety. In light of this, [2] emphasis that pharmacovigilance heavily focuses on Adverse Drug Reactions (ADRs), which are defined as any response to a drug which is noxious and unintended, including lack of efficacy. It can also be a special field of study that is concern with effect-and-benefit analyses to drug, that is, it is geared towards ensuring a possible removal of adverse drug effect on patients. Pharmacovigilance is concern with overseeing the chain of activities from the production point of the drug to the final consumption of same drug by the patients and giving necessary feedbacks to producers on the need to improve, discard drugs proven to have adverse negative effect on their health. Pharmacovigilance is the ongoing process to monitor drug safety and to make available new information and knowledge about ADRs [3]. This entails the fact that it involves the acting of inculcating desirable skills and competence on a person through awareness through safety measures. Pharmacovigilance is a cyclic process of signal detection, signal strengthening and follow up ISoP [4]. In same similitude [5] opined that pharmacovigilance is aim at 
early recognition of previously unknown adverse drug reactions (ADRs), recognition of frequency of known ADRs, identification of risk factors and mechanism of ADRs, quantitative analysis of benefit/ risk ratio and dissemination of safety information for rational drug prescribing and regulation.

While medication errors and product quality concerns have always been important aspects of drug safety surveillance, their integration into pharmacovigilance systems has increased in recent years [6]. The scope of drug safety surveillance is expansive and is becoming increasingly complex because the safety of a medicine is related not only to its pharmacological properties but also to how it is used in actual practice and to the integrity of the product's quality throughout the supply chain [7]. Pharmacovigilance is concerned with identifying the health hazards associated with pharmaceutical products and with the aim of minimizing the risk of any harm/ hazard that may come to patients [2]. It is pertinent to point out that, it tend to assist in marketability of a given pharmaceutical drug to a target population through a techniques of removal of adverse effect on a drug. Nigeria been admitted into the WHO International Drug Monitoring Programme in 2004, marked a new era of pharmacovigilance in Nigeria [8]. The National Pharmacovigilance Centre (NPC), which is an offspring under the upserges of National Agency for Food and Drug Administration and Control (NAFDAC) is charged with the task of pharmacovigilance in Nigeria. NPC serves as a repository for reported adverse drug reactions from health workers and also liaises with other international groups such as the WHO, US Food and Drug Administration and the European Medicines Agency in improving drug safety in Nigeria [8].

\section{Pharmacovigilance Department Components}

In any nation for pharmacovigilance to accomplish its set goals and objectives a pharmacovigilance department components depicted below must be functional (Figure 1).

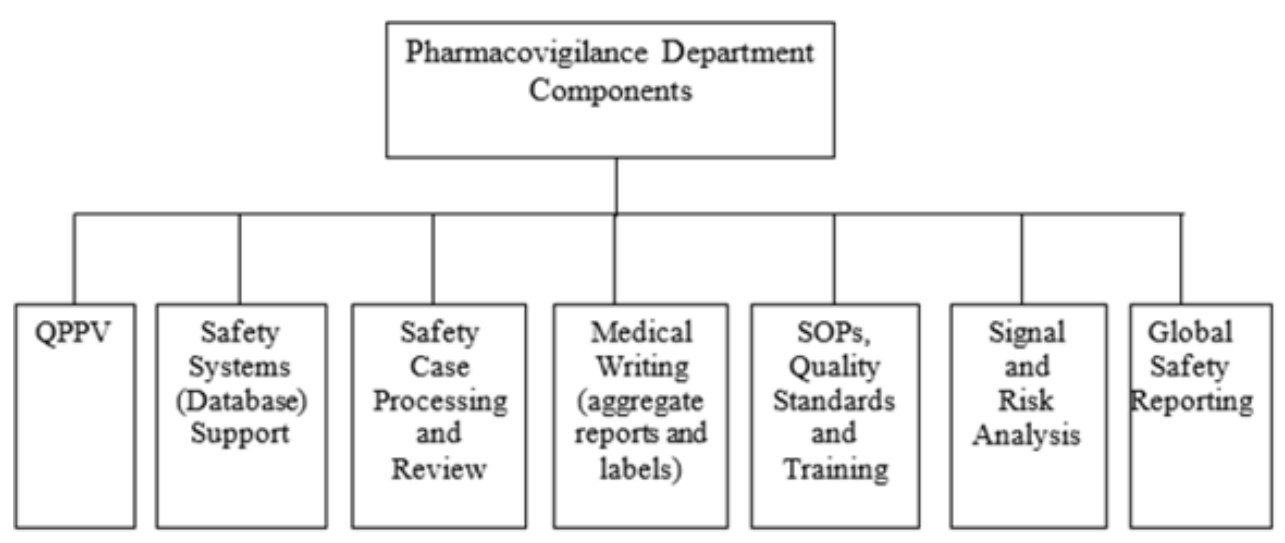

Figure 1: Adopted from Gagnon, et al. [5].

\section{Qualified Person for Pharmacovigilance (QPPV)}

These are pharmacologists who have the needed skills and competency in ensuring that the entire process of drug safety/drug surveillance is accomplished. In other words, QPPV are specialist embedded with saleable and working knowledge on ensuring surveillance on drug in a nation to avert adverse drug reaction on patients. Considering the forgoing, they ensure drug effectiveness and efficacy which will in the long-run enhance public health. It comprises of pharmacologist and some health stakeholders.

\section{Safety System Support/Data Base Support}

The safety system support comprises of safety catalyst for ensuring drugs safety by QPPV personnel. Data base support comprise of a body of information warehouse that will help to achieve drug safety cases of either adverse drug reaction or way of enhancing drug safety surveillance. The data base/safety system support assists the QPPV in storage, retrieval of proven information about drug safety. The data base helps to facilities practitioner on pharmacovigilance.

\section{Safety Case Processing and Review}

This revolves round the examining a particular drug which is observed to have an adverse effect on a given national of a nation. Here, enormous data are gathered which will assist the QPPV in discharging their job effectively.

\section{Medical Writing (Aggregate Report and Labels)}

Here, the QPPV report cases of perceived effect of drugs on a patient(s). It involves reporting a particular case of harmful drug on patients. This is done in other to ensure absolute reduction or even banning of harmful drug which on the long-run will help in the process of drug safety.

\section{Standard Operation Procedure (SOPs)}

Standard operation procedure assists in standardizing a given drugs for the betterment of patients' health condition. SOPs help to ensure quality assurance in the production quality of a particular drug. 


\section{Signal and Risk Analysis}

In this component, the QPPV intensify efforts in noting sign and risks of drugs on patients. In other words, drugs are taking into absolute consideration by QPPV through effects-benefits approaches in ensuring drug safety.

\section{Global Safety Reporting}

This involves information channeling among QPPV in a particular nation and among nations of the world. Global safety reporting involves a global drug safety surveillance. In other words, global safety reporting involves a global pharmacovigilance. Global pharmacovigilance capacity allows round-the-clock pharmacovigilance [5].

\section{Challenges Facing Pharmacovigilance in Nigeria}

In developing countries such as Nigeria, the following are some of the challenges facing pharmacovigilance.

\section{Lack of Skilled/Qualified Manpower}

In any country of the world be it developed, developing or less developed the benefit of qualified manpower cannot be overemphasized in manning any institution -learning, health among others. Nigeria been among developing countries, due to lack of skilled/qualified manpower the task of pharmacovigilance as put forward by [6] that pharmacovigilance system must continue to engage practitioners to submit high-quality reports of suspected adverse drug reactions has been hindered. Lack of qualified manpower impedes the progressive actualization of drug safety. This may be due to the fact that most of the personnel for pharmacovigilance have little education experience on how to perform their job of ensuring that pharmaceutical drug does not have negative effect on patients. In line with the forgoing, [15] noted that insufficient manpower contributed to poor development of pharmacovigilance.

Similarly, those who seems to be qualified in engaging in drug safety process are predisposed to theoretical aspect as a substitute for practical aspect of pharmacovigilance which is usually a field and experimental study. In a different development, there seems to be lack of in service training for members of the national pharmacovigilance centre (NPC) in Nigeria. It is worth noting that in-service training is an effective means of raising competencies of QPPV involved in the safety process of pharmaceutical drugs and especially those in the National Pharmacovigilance Centre (NPC). Observation seems to show that little effort has been taking concerning staffs training, while they perform their professional responsibilities. This is due to the reduction in the number of QPPV who may intend to study abroad to learn a specific course so as to improve the quality of pharmacovigilance in Nigeria with best global practice. Lack of in-service training does not only hinder practitioners in the discharge of their duties effectively, but on the aggregate actualization of pharmacovigilance objectives in Nigeria.

\section{Lack of Sufficient Funding}

Adequate funding is a driving force to achieve a predetermined outcome in any organization, establishment or facet of human endeavor. Pharmacovigilance in Nigeria has not in recent time achieved it's ultimate priority due to lack of sufficient funding from relevant stakeholder. In line with this, [16] study revealed poor budgeting for pharmacovigilance in Nigeria. This scenario has hindered mostly the monitory, assessment and detection of drugs adverse effect on patients. Additionally, pharmacovigilance personnel's do not embark on emergence inspection of some pharmaceutical establishments and other related bodies involves in drug production due to insufficient fund. This may be due to the fact that such fund if sufficient would have cater for their transport and other welfare packages among others in the process. In same view of lack of sufficient funding has overtime led to lack of appropriate facilities. In Nigeria there are no sufficient facilities such as equipped laboratories, tablet testing equipment among other to carry out effective and efficient pharmacovigilance. Due to this fact most pharmaceutical drugs that are considered sub-standard infiltrate the market for patients, and the resultant effect is of national concern. Sequence to this odd situation, pharmacovigilance has not yielded much result as anticipated by relevant stakeholders.

\section{Corruption}

Corruption is a continental problem, which has deepened itself in the vein of every society. Corruption is used to describe all forms of unprofessional ethical behavior such as bribery, illegal gratification and so forth that tends to hinder the actualization of corporate goals/objectives of an establishment. It is observed that most personnel involve in pharmacovigilance often compromise, in terms of taking bribes, and other form of illegal gratification from individuals, pharmaceutical outlets and companies who ought to be penalized for producing harmful drugs for patient consumption. This in recent time might be due to the wide economic gyration facing National Pharmacovigilance Centre (NPC) personnel's in Nigeria, which may propel them to take unlawful gratification at the detriment of the job they are set to do. It is worth noting that most times in Nigeria, when new drugs are introduced into the market some QPPV and assessment officials are giving money for such drug to be accepted, hence much assessment is not done on such drug due to the gratification made by the producers or other third parties in the chain of distribution of the said drug.

\section{Lack of Communication}

Pharmacovigilance process requires utmost communication among patients, pharmaceutical agent, NPC personnel and other stakeholders. In Nigeria there seems to be lack of keen communication among various stakeholders that would have ensure a smooth pharmacovigilance. Most times patients often find 
it difficult to report cases of adverse effect of a drug to the NPC and other relevant agencies involved in drug safety. Overtime this has led to increase rate of death per-head of patients. Similarly, most agents in the chain of distribution of drug find it difficult to report cases of drugs considered to be harmful to patient's to the National Pharmacovigilance Centre (NPC) for upward review. But, some report from patient on the effect of a given drug seem to be not only time wastage but also futile exercise. In line with the forgoing $[8,9]$ supplemented that information from patients is often not useful.

\section{Lack of Prerogative to Persecute Defaulters}

Persecution prerogative is an important aspect for effective drug safety. In developing countries of the world such as Nigeria, there is usually lack of the prerogative to persecute individuals who are involved in one form of unethical/unlawful production, distribution and sales of pharmaceutical products. Most defaulters often apprehended due to political and partisan politics are pardon in the corridor of man-know-man, political appointment and monetary gains. This scenario has open door for most individual to carry out illegal practices in the pharmaceutical environments.

\section{Challenges of Strong Collaboration}

Collaboration is a driving force for ensuring the achievement of a set goal. Pharmacovigilance requires keen collaboration from all health stakeholders. In light of this [6], noted that pharmacovigilance is a collaborative endeavor. In the process of carrying out the task of drug safety by practitioners, there seems to be no collaboration with other agencies. This may be due to its broad scope, pharmacovigilance systems cannot function in isolation from other public health agencies [6]. In Nigeria lack of strong collaboration tends to retard the effort of NPC official involves in ensuring drug safety. This lack of strong collaboration has resulted in lack of sufficient awareness programs for pharmaceutical practitioners and other health practitioners. Most patients are not given the adequate information on how to ensure drug safety during attending to the health challenges they face. In same vein, [10] submitted that most doctors know about the pharmacovigilance programme, there are some who still do not. Similarly, patients often do not have adequate understanding of patient-directed prescription drug information [11-13] this may be due to non-sensitization of patients through prior channels of information dissemination, such as the radio, television, internet, magazine among others. Due to this fact, most patients, doctors and other relevant health stakeholders that would have helped in actualization of the goal and objectives of pharmacovigilance tend to be render unproductive.

\section{Possible Solution}

For pharmacovigilance to surmount the challenges it face in Nigeria, the following aspect should be taking into keen consideration.

\section{Training and Retraining of Needed Manpower}

Training and retraining is a form of in-service or on-the-job training for increasing workers productivity. Training and retraining help to upgrade the skill, knowledge and competencies of QPPV involve in drug safety. Considering this, Pan [6] suggested that more involvement of health professionals in pharmacovigilance, their education would ideally include instruction on recognition of drug-induced disease and adverse drug reactions, on the need to be engaged with pharmacovigilance systems and on the characteristics of a high-quality, though concise, case report. This may involve the QPPV undergoing short courses programme so as to discharge their duties more efficiently and effectively. Similarly, it can be done by organizing workshops, seminars, symposia and field-trips for QPPV which will help them in improving their work performance.

\section{Supply of Sufficient Funds}

Provision of sufficient fund is keen for enhancing the entire process of ensuring pharmacovigilance in Nigeria. Sufficient fund is a phase of non-human resources that can aid pharmacovigilance in Nigeria to an advance global setting. In line with this [6] supplements that pharmacovigilance requires resources and is expected to protect and improve public health. Provision of such fund will help the QPPV for pharmacovigilance to undertake some field surveillance of some pharmaceutical drug, thus aiding their pro-activeness in their job engagement mechanism. Additionally, sufficient fund will helps in the provision of necessary facilities and equipment's. For effective and efficient pharmacovigilance to be carried out, adequate facilities must be provided to assist NPC personnels in process. Provision of infrastructural facilities and equipment's such as laboratories, tablet testing equipment (such as friability testers, dissolution samplers, refractometers, powder handling among others) which will assist NPC personnel's to ensure that pharmaceutical drugs that are detrimental to patient's health do not penetrate the market. In other words, provision of these facilities will help to ensure effective detection, assessment and monitory of drug is done, hence removing drugs considered to have negative effect on the wellbeing of patients. Similarly, this will assist persons for pharmacovigilance to carry out their job efficiently without any hindrance which was often encountered by them due to lack of these facilities.

\section{Awareness Campaign}

Awareness is a means of enlighten the public about a given issue of concern which seems to affect them. Awareness campaign helps to enlighten patients, QPPV and other health stakeholders on drug safety measures. Awareness campaign adopt various agent of communication such as television, radio, newspapers, to relay information to patients. In light of this, Dal Pal [6] submitted that pharmacovigilance systems must also provide patients and practitioners with useful, actionable information about medicines. 
This will assist Nigerians to report cases of adverse drug reaction of pharmaceutical product on their health. Similarly, it will avail qualify person for pharmacovigilance of the opportunity of being enlighten on how to ensure drug safety practice.

\section{Proper Remuneration of Qualified Persons for Pharmacovigilance (QPPV)}

Remuneration is a motivating variable that cater for workers welfare. Proper remuneration of QPPV in the National Pharmacovigilance Centre (NPC) in terms of payment of salaries, giving accrued benefit as at when due will help to reduce the level of illegal gratification and corruption among some of the QPPV. This is due to the fact that in recent time most drugs at pharmaceutical store do not pass required test, but due to corruption they are usually approved not with standing the adverse effect on patients. Additionally, this will pave way for adherence to ethical norms that will help to actualize drug safety practices in Nigeria.

\section{Constitutional Backing to Persecute Erring Persons}

In Nigeria for pharmacovigilance to be effectively carried out, there must be a constitutional provision for qualified persons for pharmacovigilance (QPPV) that will empower them to persecute defaulters. This will assist them to discipline and persecute anybody within the chain of production and distribution find engaging in unlawful practice that will on the long-run have a negative effect on patients. Similarly, this will serve as a deterrent for unethical practices in drug chain - that is from production to final patients. Additionally, it will help people to reframe from unaccepted practices that could hinder drug safety in Nigeria.

\section{Conclusion and Recommendations}

Pharmacovigilance is a substantial outfit that is geared towards actualization of drug safety in Nigeria. In-spite of the challenges facing NPC in Nigeria, if proactive measures as enunciated by the researcher are considered, it will help to unravel the ugly trend facing pharmacovigilance. In same vein the researcher wishes to recommend among other things that;

a) The Nigeria Government should collaborate with international bodies such as World Health Organization (WHO), International Council for Harmonization (ICH), Council for international Organization of Medical Science (CIOMS), International Society of Pharmacovigilance (ISoP) and other relevant agencies in other to improve pharmacovigilance in Nigeria. This will also help in knowledge sharing to improve the competencies of persons for pharmacovigilance and generally the NPC. b) The Nigeria Government should ensure that only qualified persons especially pharmacologist are employed in National Pharmacovigilance Centre (NPC). This will help in the actualization of pharmacovigilance without any hindrance resulting from incapacitated personnel.

\section{References}

1. (2002) World Health Organization (WHO) The Importance of Pharmacovigilance: Safety Monitoring of Medicinal Products. Geneva: WHO.

2. Wikipedia (2006) Pharmacovigilance.

3. Santosh KC, Tragulpiankit P (2011) Pharmacovigilance: An Overview. Journal of Pharmaceutical Science 40(12): 1991-2004.

4. (2005) International Society of Pharmacovigilance Drug Safety. New Zealand.

5. Gagnon S, Schueler Please, Fan J, Baidu More, Chin Richard (2005) Global Clinical Trial Play Book.

6. Dal Pan JG (2014) Ongoing Challenges in Pharmacovigilance. Drug Saf 37(1): 1-8.

7. Moore N, Paux G, Begaud B, Biour M, Loupi E, et al. (1985) Adverse Drug Reaction Monitoring: Doing it the Frenchway. Lancet 2(8463): 10561058.

8. Olowofela A, Fourrier Réglat A, Ambrose O Isah OI (2006) Pharmacovigilance in Nigeria: An Overview. Pharmaceutical Medicine 30: 87-94.

9. Winterstein AG, Linden S, Lee AE, Fernandez EM, Kimberlin CL (2010) Evaluation of Consumer Medication Information Dispensed in Retail Pharmacies. Arch. Intern Med 170(15): 1317-1324.

10. Vallano A, Cereza G, Pedros C, Aguti A, Danes I (2005) Obstacles and Solutions for Spontaneous Reporting of Adverse Drug Reactions in the Hospital. Br J ClinPharmacol 60(6): 653-658.

11. Enger C, Younus M, Petronis KR, Mo J, Gately R (2013) The Effectiveness of Varenicline Medication Guide for ConveyingSafety Information to Patients: a REMS Assessment Survey. Pharmacoepidemiol Drug Saf 22(7): 705-715.

12. Wolf MS, Davis TC, Shrank WH, Neuberger M, Parker RM (2006) Critical Review of FDA-Approved Medication Guides. Patient Educ Couns 62(3): 316-322.

13. Wolf MS, King J, Wilson EA, Curtis LM, and Bailey SC (2012) Usability of FDA-Approved Medication Guides. J Gen Intern Med 27(12): 1714-1720.

14. Svarstad BL, Mount JK, Tabak ER (2005) Expert and Consumer Evaluation of Patient Medication Leaflets Provided in US Pharmacies. Journal of America Pharmacy Association 45(4): 443-51.

15. Maigetter K, Pollock AM, Kadam A, Ward K, Weiss MG. (2015) Pharmacovigilance in India, Uganda and South Africa with reference to WHO's minimum requirements. Int J Heal policy Manag 4(5): 295-305.

16. Opadeyi OA, Fourrier-Réglat A, Isah OA (2018) Assessment of the state of pharmacovigilance in the South-South zone of Nigeria using WHO pharmacovigilance indicators. BMC Pharmacol Toxicol 19(1): 27. 